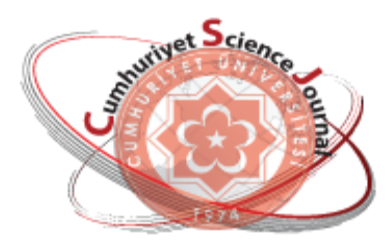

e-ISSN: $2587-246 X$

ISSN: $2587-2680$

\section{Cumburiy ot Scionee Journal esg}

Cumhuriyet Sci. J., Vol.40-4 (2019) 939-945

\title{
CT and MRI Medical Image Fusion Using Discrete Wavelet Transform
}

\author{
Molham Moshantat $^{1}$ (D), Saeid Karamzadeh ${ }^{2}$ (D) \\ ${ }^{1}$ Electrical and Electronics Engineering, Istanbul Aydin University, Istanbul, TURKEY \\ ${ }^{2}$ Electrical and Electronics Engineering Department, Faculty of Engineering and Natural Sciences, Bahçeşehir \\ University, Istanbul, TURKEY
}

\begin{abstract}
In these days, using medical image is very important in hospitals. These medical images give a lot of data about human body for example Computed Tomography (CT) identifies the bone structure, Magnetic Resonance Image (MRI) image gives information about tissue data, Positron on Emission Tomography (PET) and Single photon release computed tomography (SPECT) give human body functionality data. but these images can't give clear data image for disease diagnosis and treatment planning. So, these different modality complementary data for effective disease analysis is required. In this work we fused two images (CT and MRI) by using discrete wavelet transform then applied this transform on all types of wavelets (haar, Daubechies, Mexican Hat, Symlets, Morlet, Shannon).

Keywords: Image fusion, DWT, PSNR, IDWT, CT, MRI, Entropy.

\section{Ayrık Dalgacık Dönüşümü ile CT ve MRI Medikal Görüntü Füzyonu}

Özet. Günümüzde medikal görüntülerin teşhis ve tedavide büyük bir rol oynadığı aşikardır. Daha fazla bilgi taşıyan ve birden fazla görüntünün füzyonundan ulaşan bir görüntü bu sürece katkı sağlayacaktır. Bu çalışmada ise, CT ve MRI görüntülerinin füzyonu için, literatürde bilinen en iyi füzyon yöntemlerinden bir olan dalgacık dönüşümü uygulanmıştır. Farklı dalgacık dönüşümleri kullanılıp sonuçları sunulmuştur. Çıkan sonuçların karşılaştırılması için entropi ve sinyal, gürültü oranı (SNR) ölçülüp verilmiştir.
\end{abstract}

Anahtar Kelimeler: Dalgacık Dönüşümü, Görüntü Füzyonu, Entropi.

\section{INTRODUCTION}

These days, with the accelerate advancement in high-technology and contemporary instrumentation, medical imaging is now an essential part of a high number of applications, such as diagnosis, research, and treatment, for medical examination, just one sort of image might not be enough to supply accurate clinical prerequisite for doctors. Consequently, the combination of this multi-modal medical images is required [1]. Medical imaging provides many modes of images information for the clinical examination including CT, X-ray, DSA, MRI, PET, SPECT etc. Different medical images have different features, which may provide structural knowledge of distinct organs. By way of instance, CT (Computed tomography) and MRI (Magnetic resonance image) with high spatial resolution might offer anatomical construction info of organs. Thus, an assortment of imaging to get the exact same organ, they're contradictory but interrelated and complementary. As a result, the right image fusion of distinct features becomes an urgent 
necessity for clinical examination [2]. in this work we designed a program to merge two medical image (MRI and CT) using wavelet transform (Discrete Wavelet Transform) and discussed the best result when applied to all types of wavelets on this image and we used image fusion technique are performed on medical image utilizing wavelets like $\mathrm{db}$, coif, sym, dmey, bior, rbio and haar. These fusion Algorithms are analyzed using different performance parameters like Entropy, PSNR, SD, SNR to choose the better methods.

\section{MEDICAL IMAGE FUSION USING WAVELET TRANSFORM}

MRI and CT images usually contain individual information such as the condition and spread of the disease or details of the tissues in the human body, this section we briefly explain Digital imaging and communication in medicine (DICM) images and discusses the application of DWT fusion rule in complex wavelet domain as an approach to combine the complementary information from both the images into a single one for precise diagnosis [3-4].

\subsection{Digital Imaging and Communication in Medical}

Through the last thirty decades, there has been a huge development of digital technology. Computers have entered almost every part of their lives, so of course they have become increasingly important in medical applications. Much medical imaging methods utilized today mostly rely on computer processing. Computers are used not merely to show or store pictures but to make pictures or 3D models from the input of data. Data are obtained from imaging apparatus that use complicated processes, including CT, MRI, SPECT, PET. Furthermore, there's turned into a large, less or more powerful, development of computer-aided diagnosis (CAD) methods $[5,6]$. Due to many directions in the evolution of medical imaging equipment, it was quite essential to creating a standard for connection and information flow between appliances. As there are numerous manufacturers that produce medical imaging equipment with numerous approaches, obtaining a standard makes use of the picture and healthcare information easier. This standard is made by workgroups a year to fulfill any medical branch [7]. DICOM (Digital Imaging and Communication) Standard consists of many layers in regard to ISO (international standers organization) OSI (open systems interconnection) network design. DICOM is independent of the surface since it doesn't establish a physical link. upper layer protocol (ULP) is described within the DICOM standard. It's an abstract protocol which defines information encapsulation and is greater than level five of the ISO OSI model.

\subsection{Medical Image Fusion Using Discrete Wavelet Transform}

Modalities like CT and MRI generally contain solitary information i.e. either demonstration of disease extent or the details of soft tissues. It's practically not possible to capture each detail from 1 imaging modality that will ensure clinical precision and robustness of the investigation and consequent identification. Figure 1 shows the 3 major concentrated areas of research in medical image combination: (a) Identification, improvement and development of imaging modalities useful for medical image fusion (b) Development of different techniques for medical image fusion (c) Application of medical image fusion for studying human organs of interest in assessments of medical condition Various approaches are available for graphic mix applications, but image fusion techniques are essentially categorized into two broad classes i.e. spatial domain Fusion and Transform domainbased fusion.

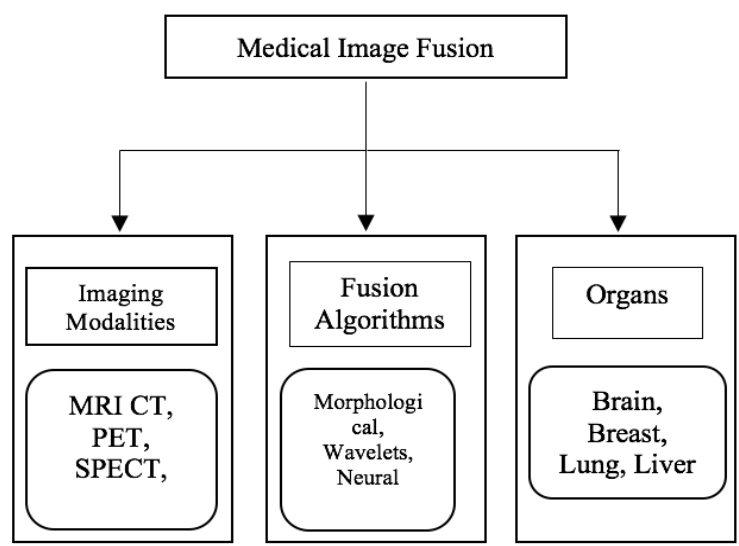

Figure 1: Nature of modalities, methods and organs used in medical image fusion [11]. 
The first idea and concept of wavelet-based multiresolution analysis came from Mallat. A wavelet transform is a mathematical tool which could detect local attributes in a signal process. Additionally, it may be utilized to segregate two dimensional (2D) signs like 2D gray-scale image signals into various varying levels for multiresolution analysis. Wavelet transform has been heavily utilized in several locations, including texture analysis, data compression, feature detection, and image fusion.

In one dimension (1D) the basic idea of the DWT is to represent the signal as a superposition of wave lets. Suppose that a discrete signal is represented by $\mathrm{f}(\mathrm{t})$ the wavelet decomposition is then defined as

$$
f(t)=\sum_{m, n} c_{m, n} \psi_{m, n}(t)
$$

Where $\psi m, n(t)=2-m / 2 \psi[2-m t-n]$ and $\mathrm{m}$ and $\mathrm{n}$ are integers. Wavelet transform for image fusion the schematic diagram for wavelet based fusion techniques is shown in figure 2.
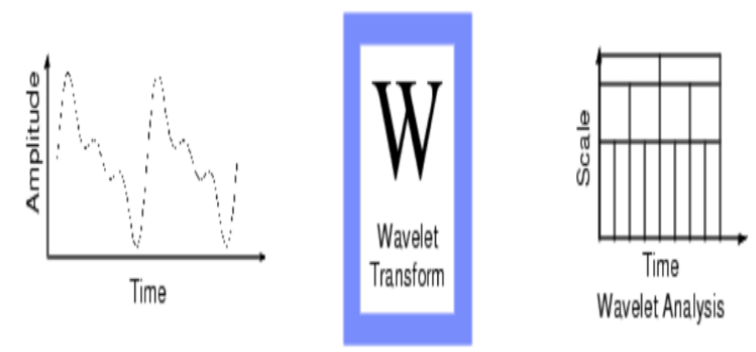

Figure 2: Wavelet Transform on a signal [10].

In all wavelet-based image fusion techniques the wavelet transforms $\mathrm{W}$ of the two registered input images are computed and these transforms are combined using some kind of fusion rule $\varnothing$. This is given by equation (2) below:

$I(x, y)=w^{-1}\left(\phi\left(W\left(I_{1}(x, y)\right), W\left(I_{2}(x, y)\right)\right)\right.$

where $\mathrm{W}-1$ is the inverse discrete wavelet transform (IDWT).

Generally, the fundamental idea of image fusion based on wavelet transform would be to execute a multiresolution decomposition on every source image; the coefficients of the low-frequency band and high-frequency bands are subsequently performed with a particular mix rule. Following that, the fused image is accessed by doing the inverse DWT (IDWT) for its corresponding combined wavelet coefficients $[8,9]$.

\subsection{Algorithm:}

Following algorithm has been developed and implemented in MATLAB software:

1. Read the image I1 and find its size.

2. Read the second image I 2 and find its size.

3. Compute and match the size if not same, make it same.

4. The indexed image should be DICOM.

5. Perform multilevel wavelet decomposition using any wavelet (haar, $\mathrm{db}$, bior...). Generate the coefficient matrices of the level-three approximation and horizontal, vertical and diagonal details.

6. Now fuse the wavelet coefficients using discrete wavelet transform.

7.Generate a final matrix of fused wavelet coefficients.

8. Compute the inverse wavelet transform to get the fused image.

9. Finally compute the entropy, SD, PSNR, SNR and display the results

The block diagram for image fusion is shown in figure 3 .

\section{RESULT AND DISCUSSION PERFORMANCE ANALYSIS}

This paper aims to present a new algorithm to improve the quality of multimodality medical image fusion using discrete wavelet transform (DWT) approach. performance of fusion is calculated on the basis of entropy, SD and PSNR. The total processing time and the results demonstrate the effectiveness of fusion scheme based on wavelet transform. MRI and CT images are taken as source images (figure 4). MATLAB is used for the simulation. 


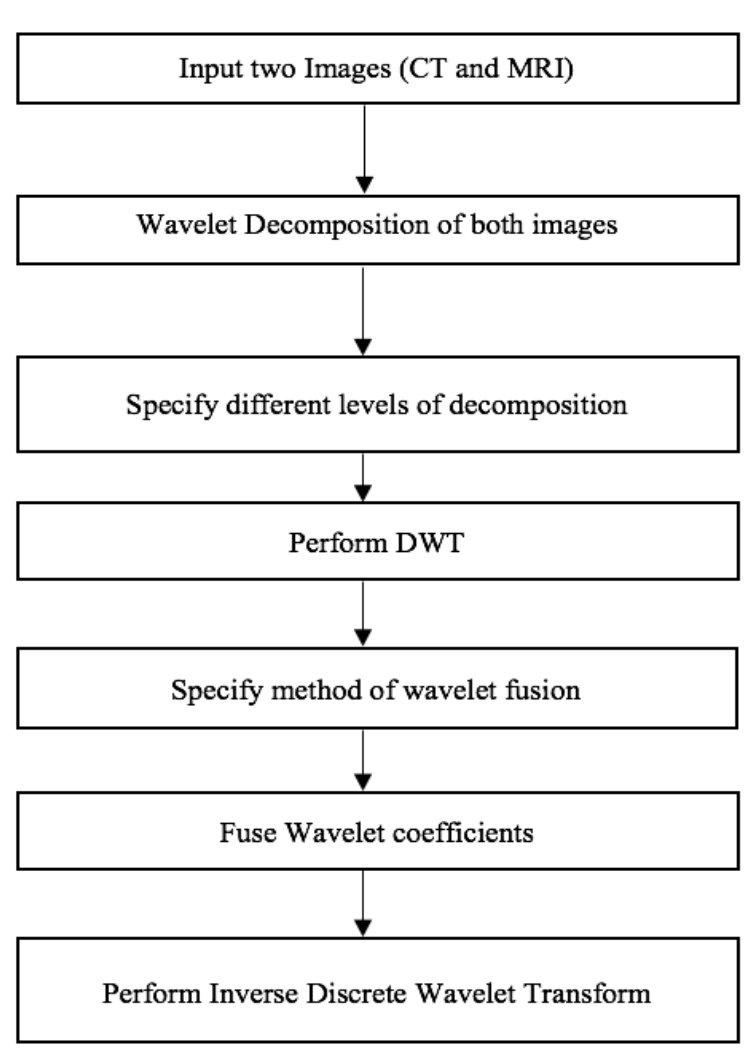

Figure 3: Block diagram for image fusion.

Fusion is performed on source images using different wavelets like db, coif, sym, dmey, bior, rbio and haar. The MRI \& CT medical images (figure 4) are used for the fusion experiment. The simulations are performed on these MRI and CT Medical images for 7 different wavelets transform methods (Bior, coif, db, dmey, haar, rbio and sym). In the whole work the Max- Max wavelet coefficient with level-1 has been used.

\subsection{Entropy}

Entropy has been used in several scientific areas in addition to in image processing procedures and it includes the data content of image. Entropy is a parameter to value the information quantity in image. Entropy defines the info in the electronic numbers in images because of a frequency of modification.

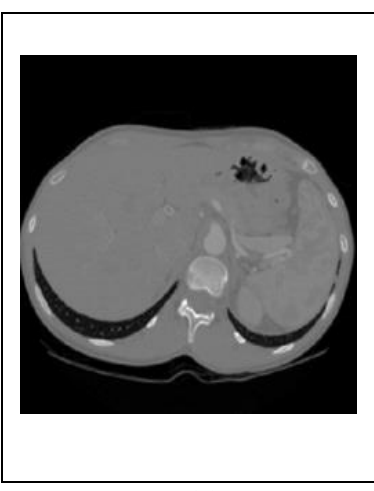

(a)

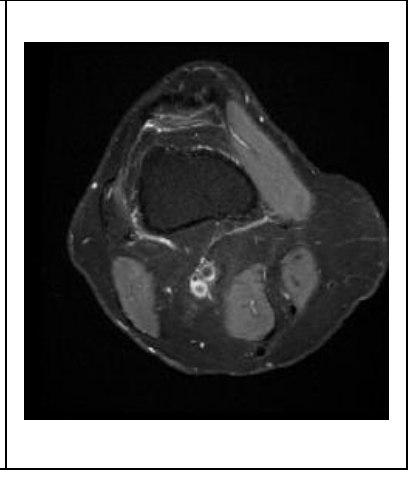

(b)
Figure 4: a) MRI image that we used in our program,

b): CT image that we used in our program [7].

When every grey level has the exact same frequency, then the entropy gets the highest value. Quality evaluation is essential as Imaging techniques such as the fusion algorithm can present a few quantities of artifacts or distortion in the signal. For quality evaluation, entropy is employed to appraise the data quantity in image. The greater value of entropy suggests the revised image is far better than the benchmark image that has more contrast and clarity and is your best image to use for medical purposes. In case entropy of fused image is greater than the source image then it suggests the revised image contains more info than source image and the fused performances are enhanced [12]. Entropy Provides the amount of Data contained in the image, the Further information it Comprises, entropy is defined as:

$H=-\sum_{i=1}^{M} \sum_{j=1}^{N} p_{i j} \log _{2} p_{i j}$

$p_{i j}=\frac{f(i, j)}{\sum_{i=1}^{M} \sum_{i=1}^{N} f(i, j)}$

Where $\mathrm{H}$ represents the regional information entropy, pij is the gray value probability of point ( $i$, $j$ ) in the regional image, $f(i, j)$ is the gray value of point $(i, j)$ in the regional image. The size of the region is $\mathrm{M}^{*} \mathrm{~N}$. The entropy value is 0 when no texture is in the image. The entropy is maximized when full of texture is in the image. The entropy value in our proposed work is shown in table 1 shown that fused image using biorthogonal wavelets have the highest value compering with other wavelet which mean this result will give us more details than source image. 


\subsection{Standard Deviation:}

Standard deviation calculates the quantity of grey values which are dispersed in image. In the event of the image fusion, standard deviation measures the comparison of the fused image. [13] High quality of standard deviation is obtained from the absence of noise.

\subsection{Peak Signal To Niose Ratio (PSNR):}

PSNR is your measure of ratio between the highest value of image and the size of the noise present in the image background. Normally PSNR is utilized to assess the reconstruction quality of fused image It suggests that the similarity between two images, the PSNR defined as:

$$
\begin{aligned}
& P S N R=10 \frac{\log _{10}(255)^{2}}{M S E} d B \\
& M S E=\frac{1}{M N} \sum_{i=1}^{M} \sum_{k=1}^{N}\left(x_{j, k}-\tilde{x_{j, k}}\right)
\end{aligned}
$$

MSE is the mean square error representing the difference between the original cover image sized $\mathrm{N} \times \mathrm{N}$ and the stego image sized $\mathrm{N} \times \mathrm{N}$, and the $x(j, k)$ and $x^{\prime}(j, k)$ are pixel located at the jth row the kth column of images $x$ and $x^{\prime}$, respectively.

A large PSNR value means that the stego image is most similar to original image and vice versa. It is hard for the human eyes to distinguish between original cover image and stego image when the PSNR ratio is larger than $30 \mathrm{~dB}$.

The PSNR value our proposed work is shown in table 1 shown that biorthogonal wavelets value is 21.7275 which is the highest result and less than $30 \mathrm{~dB}$ which mean the human eyes can recognition the different between the resulting images.

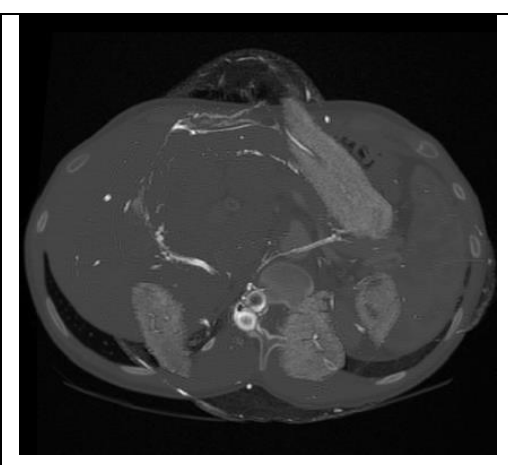

(a)

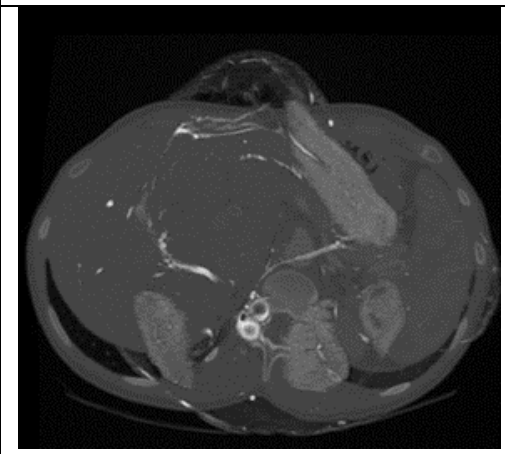

(d)

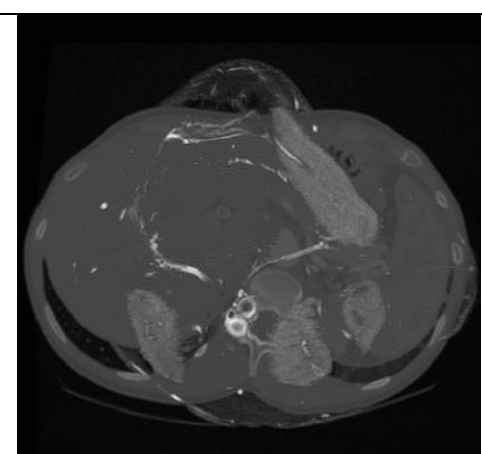

(b)

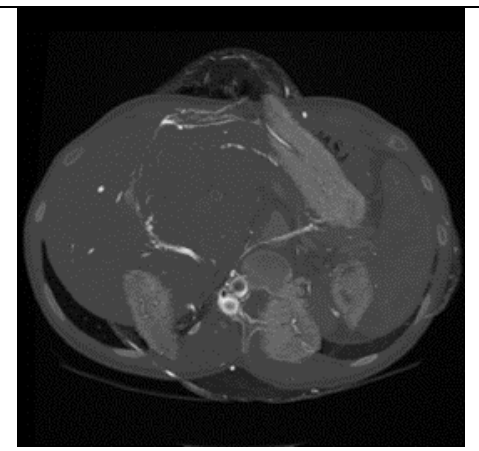

(e)

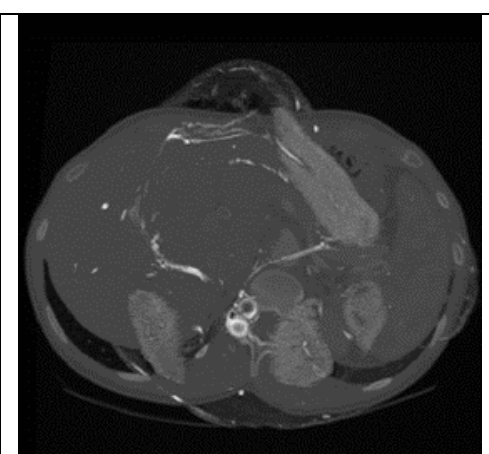

(c)

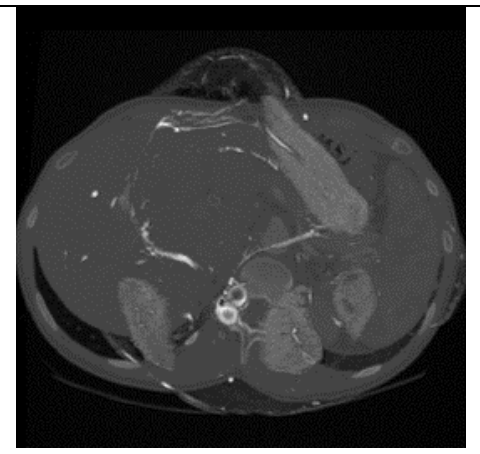

(f)

Figure (5): The image resulting from the application a): haar wavelet, b): application Discrete approximation of Meyer wavelet c): Daubechies Wavelets , d): Symlets wavelets, e): Biorthogonal wavelets, f): Reverse biorthogonal wavelets. 


\section{3 signal-to-noise ratio (SNR):}

Quantification of this signal-to-noise ratio (SNR) is important in image acquisition processes in electron microscopy and other areas where the image is degraded by noise. Specifically, together with scanning electron microscopy (SEM), the tradeoff with image resolution is usually SNR. The definition of SNR varies based on this area [14]. In electrical engineering and statistical optics, it's defined as the power (variance) ratio between noise and signal, whilst at the electron microscopy that the square root of the amount is usually believed, it is given by

$S N R=10 \log _{10} \frac{\sigma_{x}^{2}}{\sigma_{s}^{2}}$

The SNR value in our proposed work is shown in table 1 shown that best result is biorthogonal wavelets compare with another wavelet.

Table 1: The result for merged image

\begin{tabular}{|l|l|l|c|c|}
\hline \multirow{2}{*}{ Wavelet } & \multicolumn{3}{|c|}{ Analyze Performance } & \\
\cline { 2 - 5 } & Entropy & \multicolumn{1}{|c|}{$\boldsymbol{P S N \boldsymbol { R }}$} & $\boldsymbol{S} \boldsymbol{D}$ & $\boldsymbol{S} \boldsymbol{R}$ \\
\hline Haar & 5.7060 & 21.1426 & 0.1423 & 7.9962 \\
\hline dmey & 5.6236 & 21.2663 & 0.1410 & 8.1435 \\
\hline Db9 & 5.6523 & 21.1470 & 0.1424 & 8.0877 \\
\hline Conif1 & 5.6611 & 21.3843 & 0.1419 & 8.2876 \\
\hline Sym3 & 5.6857 & 21.2875 & 0.1414 & 8.2626 \\
\hline Bior1.3 & 5.7202 & 21.2949 & 0.1424 & 8.1692 \\
\hline Rbio3.1 & 5.7598 & 21.7265 & 0.1431 & 10.264 \\
\hline
\end{tabular}

\section{CONCLUSIOONS}

In this paper, the image fusion of MRI \& CT medical images is done using fully automated wavelet transforms in MATLAB environment. 3The different fusion methods used are - Bior, coif, $\mathrm{db}$, dmey, haar, rbio and sym. Further the comparative analysis of image fusion techniques helps in selecting the best fused image and therefore can provide better visualization of the fused image. The synthesized image has the qualities of both MRI \& CT fused images. After the fusion of the images, it is concluded that the best synthesized image at level 1 with max-max method is Rbio3.1. Using the entropy method as a measuring assessment it is found that the resultant
Rbio3.1 image has highest entropy (5.7598), so it is considered as the best fused image having the best quality, clarity and contrast. The worst entropy is obtained for dmey wavelet transforms. The best fused image is distinctively clear, easy to observe and thus, can be analyzed by the doctors for prescribing the proper medication for the shown ailment, in this thesis only (DWT) were investigated in Two-Dimensional. There are more tools like ridgelet transform bandelet transform grouplet transform etc. and we can use that need to be explored for image fusion and also, we can use Three-Dimensional.

\section{REFERENCES}

[1] A. Soma Sekhar, Dr.M.N. Giri Prasad., A Novel Approach of Image Fusion on MR and CT Images Using Wavelet Transforms, 3rd International Conference on Electronics Computer Technology, April (2011) 12 -86 DOI: 10.1109/ICECTECH.2011.5941881.

[2] H. H. Wang., A new multiwavelet-based approach to image fusion, Journal of Mathematical Imaging and Vision, 21 (2004) 177-180.

[3] Bernd Fischer, Jan Modersitzki., Curvature Based Image Registration, Journal of Mathematical Imaging and Vision, 18-1 (2003) 81-85.

[4] Peter Rogelj and Stanislav Kovacic., Similarity Measures for Non- Rigid Registration, Ministry of Science and Technology of the Republic of Slovenia, Research program, feb. (2001) 82-91.

[5] Ligia Chiorean, Mircea-Florin Vaida., Medical Image Fusion Based on Discrete Wavelet Transform Using Java Technology, 31st Int. Conf. on Information Technology Interfaces, June (2009).

[6] NEMA Publications., Digital Imaging and Communications in Medicine (DICOM), journal of digtal medcicin, Ver. 8.0 (2008) 8 16.

[7. https://www.dicomlibrary.com 12.11.2018 11:45. 
[8] M. Hub, M.L. Kessler, and C.P. Karger., A stochastic approach to estimate the uncertainty involved in B-spline image registration, MedImg, 28-11 (2009) 17081716.

[9] J.V.Chapnick, M.E.Noz, G.Q. Maguire, E.L.Kramer, J.J.Sanger, B.A.Birnbaum, A.J.Megibow., Techniques of Multimodality Image Registration, Proceedings of the IEEE nineteenth Annual North East Bioengineeering conference, 18-19 March (1993) 221-222.

[10] J. B. Antoine Maintz and Max A. Viergever., A Survey of Medical Image Registration, Medical Image Analysis 2-1 (1998) 1-36.
[11] Brown Gottesfeld L., A survey of image Registration Techniques, ACM Computing surveys, 24-4 (1992) 325-376.

[12] Rahul S.Shınde, AltaafO.Mulani., Biomedical Image Fusion Using Wavelet Transform, 2-10 (2015) 50-53.

[13] P. A. Van Den Elsen, E. J. D. Pol and M. A. Viergever., Medical image matching: a review with classification, IEEE Engineering in medicine and biology, march (1993) 26-39.

[14] Pelizzari CA, Chen GTY, Spelbring DR, Weichselbaum RR, Chen CT. Accurate 3dimensional registration of CT, PET, and/or MR images of the brain. J Comput Assist Tomogr, Jan-Feb. (1989) 13-20. 